\section{Psychiatric and personality disorders in deliberate self-harm patients}

CAMILLA HAW, KEITH HAWTON, KELLY HOUSTON and ELLEN TOWNSEND
Deliberate self-harm (DSH) is becoming more common (Hawton et al, 1997; Kapur et al, 1998) and is associated with significant risk of suicide (Hawton \& Fagg, 1988; Nordentoft \& Rubin, 1993). Deliberate self-harm occurs for diverse reasons, one important factor being psychiatric disorder. Earlier studies in the UK suggested less psychiatric disorder in selfpoisoning patients (Newson-Smith \& Hirsch, 1979; Urwin \& Gibbons, 1979) than in suicides (Barraclough et al, 1974). More recent studies of DSH from other countries have reported high rates of psychiatric disorder (Ennis et al, 1989; Beautrais et al, 1996; Suominen et al, 1996; Ferreira de Castro et al, 1998) which resemble those found in suicides (Barraclough et al, 1974; Foster et al, 1997). Comorbidity of psychiatric disorders was common in those studies (Beautrais et al, 1996; Suominen et al, 1996; Ferreira de Castro et al, 1998). Personality disorders were also frequent (Ennis et al, 1989; Suominen et al, 1996; Ferreira de Castro et al, 1998), although few studies have used standardised measures of personality. In this study we used a structured clinical interview and a standardised instrument to investigate the nature and prevalence of psychiatric and personality disorder in a representative sample of DSH patients in the UK.

\section{METHOD}

\section{Subjects}

The subjects were patients aged 15 years and over who presented to the district general hospital in Oxford following an episode of DSH between 10 February and 1 December 1997. The definition of DSH was as for 'parasuicide' in the WHO/Euro Multi-Centre Study on Parasuicide, namely

\footnotetext{
"an act with non-fatal outcome in which an individual deliberately initiates a non-habitual behaviour, that without intervention from others will cause self-harm, or deliberately ingests a
}

substance in excess of the prescribed or generally recognised dosage, and which is aimed at realising changes that the person desires via the actual or expected physical consequences" (Plattet al, 1992).

Thus, the definition of DSH included acts of self-poisoning and self-injury, but excluded acts of self-cutting which were part of a repetitive pattern of self-mutilation. Patients were excluded from the study if they were under the age of 15 years, lived outside the Oxford district or were unable to understand or otherwise participate in the study (e.g. medically unfit, severe learning disabilities, severe disturbance of mental state, organic brain syndrome).

The potential sample included all DSH patients who presented to the hospital and were medically fit to be interviewed on recruitment days, which included both weekdays and weekends to ensure the patient sample was distributed throughout the week. The majority of DSH patients (approximately three-quarters) who present to the general hospital in Oxford are assessed by the general hospital psychiatric service (Hawton et al, 1997). However, efforts were made to recruit patients who had not been seen by the service. Patients were approached in hospital by a member of the research team, generally following assessment by the psychiatric staff. If the patient was discharged before they could be approached, they were sent a letter, which was followed-up by a telephone call. Of 217 patients approached, 150 (69.1\%) agreed to participate in the study. The reasons for non-participation $(n=67)$ were: refused ( $n=42)$; did not reply to the contact letter $(n=16)$; and agreed, but did not attend the appointment $(n=9)$. The timing of the interviews in relation to the index episode of DSH was within 24 hours $(n=4) ; 1-2$ days $(n=68) ; 3-7$ days $(n=35) ; 1$ week to 1 month $(n=39)$ and $>1$ month $(n=4)$.

The study sample was compared with all other patients who presented to the hospital during the study period using data from the Oxford Monitoring System for Attempted Suicide, which is used to collect information on all DSH patients presenting to the general hospital, irrespective of whether or not they are assessed by the psychiatric service (Hawton et al, 1997).

\section{Research instruments}

European Parasuicide Study Interview Schedule

The schedule used in the WHO/Euro Multicentre Study on Parasuicide (Kerkhof et al, 
1989) was administered. The schedule includes the following areas of inquiry: demographic, circumstances of current and previous episodes of DSH, life events, social support, contact with health professionals and physical and mental health.

\section{ICD-10 Diagnostic Schedule}

The duration and nature of current and past psychiatric symptoms were recorded using a structured interview schedule, based strictly on ICD-10 research diagnostic criteria (World Health Organization, 1993), which was developed by our group (Hawton et al, 1998). The assessment was made according to the patient's self-report of symptoms during the period leading up to the index episode of DSH, and observation of the patient during the interview. For each category of disorder the patients were asked screening questions (essential for a diagnosis). Where there was a positive response to one or more of the screening questions, these were followed by the full list of research criteria for the specific diagnosis as listed in ICD-10. The research interviewers were trained by a medical psychiatric researcher who was very experienced in diagnostic interviewing and one researcher who also had previous experience of such interviewing.

\section{Personality Assessment Schedule}

Personality was assessed using the self-report version of the Personality Assessment Schedule (PAS) (Tyrer et al, 1988), updated according to ICD-10 criteria (World Health Organization, 1993) by Tyrer and colleagues. Ratings within each personality area were classified according to Tyrer $e t$ al's (1988) scheme, where a rating of seven or more indicated personality disorder and a rating of 4-6 trait accentuation. The PAS was completed at the follow-up interview (see below). This allowed us to assess personality when psychiatric disorder was likely to be less prominent (Zimmerman, 1994).

\section{Consensus meetings and reliability of ratings}

The research team identified psychiatric diagnoses at consensus meetings based on the information obtained from the structured diagnostic interview schedule. In a small number of cases with complex psychiatric histories, psychiatric case notes were examined to aid clarification of the diagnoses. In order to assess reliability, two psychiatrists working on the project independently reviewed the information obtained from the diagnostic interview for 20 cases. One of the psychiatrists made 32 diagnoses. The second psychiatrist was in agreement with all of these diagnoses ( $F$ code whole numbers), but also made three further diagnoses. Thus, the overall agreement was $91.4 \%$.

\section{Follow-up interview}

Follow-up interviews $(n=118)$ were conducted approximately 12-16 months after the index episode of DSH in 111 cases $(94.1 \%)$ and between $17-20$ months in seven cases $(5.9 \%)$.

\section{Statistical analyses}

The analyses were conducted using the Statistical Package for the Social Sciences (SPSS, 1999) and EpiInfo (Dean et al, 1994). The statistical tests employed were the $\chi^{2}$ (with Yates' correction, where appropriate) and Mann-Whitney $U$-tests.

\section{RESULTS}

\section{Sample}

\section{Initial interview}

Of the 150 patients included in the study, $92(61.3 \%)$ were female and $58(38.7 \%)$ were male. The majority of patients were Caucasian $(97.3 \%)$. The social class distribution of the study sample was I and II $(16.7 \%)$, IIIM and IIINM (35.3\%), IV and $\mathrm{V}(33.3 \%)$, armed forces $(2.0 \%)$ and students $(12.7 \%)$. Ninety-eight patients $(65.3 \%)$ were known to have carried out a previous episode of DSH (this includes episodes not resulting in hospital referral). The study sample was representative of the total DSH population which presented to the general hospital during the study period in terms of age, gender, previous history of DSH and whether they were currently in psychiatric care. Patients included in the study were more likely to have self-poisoned $(94.0 \% \quad v . \quad 84.7 \%$; $\left.\chi^{2}=7.97, P<0.01\right)$. This difference is likely to be due to the exclusion of patients who habitually cut themselves from the study as they did not fall within the WHO/Euro Multi-Centre Study definition of DSH.

The study sample was also compared with the remaining DSH patients who were approached to be in the study using data from the Oxford Monitoring System for Attempted Suicide in order to ensure the same source of data. The study sample did not differ from the non-included DSH patients in terms of age, gender and employment status. Somewhat more of the included patients had a previous history of DSH and were in psychiatric treatment as the time of the index attempt, although neither difference was statistically significant (see Table 1). Patients who participated in the study were more likely to have been assessed by a member of the hospital psychiatric staff.

\section{Follow-up interview}

A total of 118 patients (78.7\%) were interviewed at follow-up. Of those who were not interviewed, 10 refused, 14 could not be contacted, seven agreed but did not attend and one committed suicide during the follow-up period. The PAS was completed for 111 patients at follow-up. PAS scores were not obtained for two patients who were too mentally unwell to provide reliable information, nor for five who did not complete the follow-up interview. There was no difference between those for whom the PAS was completed and those where this was not possible with respect to gender, method of DSH, previous self-harm and psychiatric disorder at the time of the index attempt. However, those who were followed-up were somewhat younger (median 26.5 years $v$. 32.0, $U=1448$, $P<0.05)$.

\section{Psychiatric disorders}

At the time of the index episode of DSH, 138 patients $(92.0 \%)$ were diagnosed with at least one psychiatric disorder (see Table 2). A single psychiatric disorder was found in 68 patients $(45.3 \%)$, two disorders in $55(36.7 \%)$ and three or more in $15(\mathbf{1 0 . 0 \% )}$. Hence, comorbidity of two or more psychiatric disorders was present in 70 cases $(46.7 \%)$. There was no gender difference in the frequency of comorbidity of psychiatric disorders. Of the 12 patients $(8.0 \%)$ without a current psychiatric disorder, four had a past history of psychiatric disorder.

\section{Affective disorders}

Affective disorder was present in 108 patients $(72.0 \%)$. A depressive episode was present in 106 patients $(70.7 \%)$. Of the depressive episodes, $50(47.2 \%)$ were severe/psychotic, $45(42.5 \%)$ moderate, three $(2.8 \%)$ mild and eight $(7.5 \%)$ other/unspecified. There were no gender 
Table I Comparison of recruited patients with the remainder of potential patients

\begin{tabular}{|c|c|c|c|c|}
\hline & \multicolumn{2}{|c|}{$\begin{array}{l}\text { Patients included in study } \\
\qquad(n=150)\end{array}$} & \multicolumn{2}{|c|}{$\begin{array}{l}\text { Patients not included in study } \\
\qquad(n=67)\end{array}$} \\
\hline & $n$ & (\%) & $n$ & (\%) \\
\hline \multicolumn{5}{|l|}{ Gender } \\
\hline Male & 58 & $(38.7)$ & 26 & $(38.8)$ \\
\hline Female & 92 & $(61.3)$ & 41 & $(61.2)$ \\
\hline \multicolumn{5}{|l|}{ Age (years) } \\
\hline $15-24$ & 62 & $(4 I .3)$ & 26 & $(38.8)$ \\
\hline $25-34$ & 36 & $(24.0)$ & 18 & (26.9) \\
\hline $35-54$ & 42 & $(28.0)$ & 19 & $(28.3)$ \\
\hline $55+$ & 10 & $(6.7)$ & 4 & $(6.0)$ \\
\hline \multicolumn{5}{|l|}{ Employment status } \\
\hline Employed & 61 & $(40.7)$ & 24 & $(35.8)$ \\
\hline Unemployed & 34 & $(22.7)$ & 15 & $(22.4)$ \\
\hline Permanently sick & 19 & $(12.6)$ & 5 & $(7.5)$ \\
\hline Housewife & II & $(7.3)$ & 9 & $(13.4)$ \\
\hline Student & 18 & $(12.0)$ & 8 & $(I I .9)$ \\
\hline Retired & 4 & $(2.7)$ & 4 & $(6.0)$ \\
\hline Not known & 3 & $(2.0)$ & 2 & $(3.0)$ \\
\hline \multicolumn{5}{|c|}{ Method of deliberate self-harm } \\
\hline Self-poisoning & $|4|$ & $(94.0)$ & 62 & $(92.5)$ \\
\hline Self-injury & 6 & $(4.0)$ & 4 & $(6.0)$ \\
\hline Both & 3 & $(2.0)$ & 1 & $(1.5)$ \\
\hline \multicolumn{5}{|c|}{ Previous episodes of deliberate self-harm' } \\
\hline No & 47 & $(31.3)$ & 30 & $(44.8)$ \\
\hline One or more & 95 & $(63.3)$ & 33 & $(49.3)$ \\
\hline Not known & 8 & $(5.3)$ & 4 & $(6.0)$ \\
\hline \multicolumn{5}{|c|}{ Receiving psychiatric treatment at time } \\
\hline \multicolumn{5}{|c|}{ of deliberate self-harm² } \\
\hline No & 100 & $(66.7)$ & 47 & $(70.1)$ \\
\hline Yes & 45 & $(30.0)$ & II & $(16.4)$ \\
\hline Not known & 5 & $(3.3)$ & 9 & $(13.4)$ \\
\hline \multirow{2}{*}{\multicolumn{5}{|c|}{$\begin{array}{l}\text { Psychiatric assessment in hospital following } \\
\text { deliberate self-harm }\end{array}$}} \\
\hline & & & & \\
\hline No & 15 & $(10.0)$ & 14 & $(20.9)$ \\
\hline Yes & 135 & $(90.0)$ & 53 & (79.1) \\
\hline
\end{tabular}

I. $\chi^{2}=3.33, P=0.07$.

2. $\chi^{2}=2.45, P=0.12$

3. $\chi^{2}=3.85, P<0.05$ (excludes not known cases)

differences in the presence or severity of a depressive episode. Of those with a depressive episode, the length of the current episode was $2-4$ weeks in 17 cases $(16.0 \%), 2-6$ months in 38 (35.9\%), 7-12 months in $18(17.0 \%)$ and $>1$ year in $32(30.2 \%)$. It was not possible to ascertain the duration in one case. There was a past history of depressive episodes in $41(38.7 \%)$ of those with a current diagnosis of depression and in seven patients $(4.7 \%)$ without a diagnosis of depression. In addition to the patients with depressive disorders, one patient

had dysthymia and another had a bipolar affective disorder which appeared to be in remission.

Disorders with prominent depressive symptoms (depressive episode, F32; dysthymia, F34; schizoaffective disorderdepressive type, F25.1; mixed anxiety and depressive disorder, F41.2; adjustment disorder with depressive symptoms, F43.2) were present in 117 cases $(78 \%)$.

\section{Substance use disorders}

Alcohol dependence or harmful use was present in 40 patients $(26.7 \%)$. Male patients were significantly more likely to suffer from alcohol dependence or harmful use than female patients $\left(\chi^{2}=5.23\right.$, $P<0.05)$. Four males were suffering from both alcohol dependence and alcoholic hallucinosis (F10.52). A past history of alcohol dependence or harmful use was present in a further nine patients.

Drug misuse or dependence was present in 13 patients $(8.7 \%)$ and a further four patients $(2.7 \%)$ had a past history but no current drug misuse. The most common forms of drug dependency were of heroin (three cases) and benzodiazepines (three cases).

\section{Neurotic, stress-related and somatoform disorders}

Twenty-one patients (14.0\%) had an anxiety disorder. The most common anxiety disorder was social phobia $(n=9$, $6.0 \%)$ followed by agoraphobia $(n=6$, $4.0 \%)$. Other anxiety disorders present included: generalised anxiety $(n=2)$; mixed anxiety and depression $(n=2)$ and panic disorder $(n=1)$. One patient had an isolated specific phobia and no other psychiatric disorder. No significant gender differences were found in the prevalence of anxiety disorders. Three patients $(2.0 \%)$ had obsessive-compulsive disorder. Adjustment reactions $(n=4,2.7 \%)$ were uncommon. Three patients $(2.0 \%)$, all female, had post-traumatic stress disorder. One patient had dissociative convulsions. Five patients $(3.3 \%)$ had somatoform disorders, most commonly somatisation disorder $(n=3,2.0 \%)$.

\section{Eating disorders}

Eating disorders were present in 16 patients $(10.7 \%)$, with female patients predominating $\left(\chi^{2}=4.01, P<0.05\right)$. A past history of an eating disorder was found in nine female patients $(6.0 \%)$ who did not have a current eating disorder.

\section{Schizophrenia, schizotypal and delusional disorders}

Three patients had a diagnosis of schizophrenia. One patient who appeared to be developing a schizophrenic illness was classified as suffering from an 'other non-organic psychosis' as the symptoms did not meet the diagnostic criteria for schizophrenia. Four patients (all female) had a schizoaffective illness. Four patients had florid positive psychotic symptoms and four had no positive symptoms. Four were also markedly depressed. 
Table 2 Psychiatric disorders at time of index episode of deliberate self-harm

\begin{tabular}{|c|c|c|c|c|c|c|}
\hline \multirow[t]{2}{*}{ Psychiatric disorder (ICD-10 classification) } & \multicolumn{2}{|c|}{$\begin{array}{l}\text { Males } \\
(n=58)\end{array}$} & \multicolumn{2}{|c|}{$\begin{array}{c}\text { Females } \\
(n=92)\end{array}$} & \multicolumn{2}{|c|}{$\begin{array}{c}\text { Total } \\
(n=\mid 50)\end{array}$} \\
\hline & $n$ & (\%) & $n$ & (\%) & $n$ & (\%) \\
\hline Affective disorders $\mathrm{F} 30-39$ & 41 & (70.7) & 67 & $(72.8)$ & 108 & (72.0) \\
\hline Bipolar (F3I) & 0 & & I & & I & \\
\hline Depressive episode (F32) & 41 & & 65 & & 106 & \\
\hline Dysthymia (F34) & 0 & & 1 & & 1 & \\
\hline Substance use disorders: alcohol FIO' & 22 & (37.9) & 18 & $(19.6)$ & 40 & (26.7) \\
\hline Alcohol harmful use (FIO.I) & 8 & & 8 & & 16 & \\
\hline Alcohol dependence $(\mathrm{FIO} .2)^{2}$ & 14 & & 10 & & 24 & \\
\hline Substance use disorders: drugs FII-191 & 9 & (15.5) & 4 & $(4.3)$ & 13 & (8.7) \\
\hline Drug harmful use (FII.I-19.I) & 4 & & 2 & & 6 & \\
\hline Drug dependence (FII.2-19.2) & 5 & & 2 & & 7 & \\
\hline Neurotic, stress-related and somatoform disorders F40-48 & II & $(19.0)^{3}$ & 24 & $(26.1)^{4}$ & 35 & (23.3) \\
\hline Anxiety disorder (F40-4I) & 8 & & 13 & & 21 & \\
\hline Obsessive-compulsive disorder (F42) & 2 & & 1 & & 3 & \\
\hline Post-traumatic stress disorder (F34.I) & 0 & & 3 & & 3 & \\
\hline Adjustment disorder (F43.2) & 0 & & 4 & & 4 & \\
\hline Dissociative disorder (F44) & $\mathbf{I}$ & & 0 & & 1 & \\
\hline Somatoform disorder (F45) & $\mathbf{I}$ & & 4 & & 5 & \\
\hline Eating disorders F50 & 2 & (3.4) & 14 & $(15.2)$ & 16 & $(10.7)$ \\
\hline Anorexia nervosa (F50.0-50.I) & 0 & & 2 & & 2 & \\
\hline Bulimia nervosa ( $F 50.2-50.3)$ & 2 & & 5 & & 7 & \\
\hline Other/unspecified eating disorder (F50.8-50.9) & 0 & & 7 & & 7 & \\
\hline Schizophrenia and non-affective psychoses F20-29 & 3 & $(5.2)$ & 5 & $(5.4)$ & 8 & (5.3) \\
\hline Paranoid schizophrenia (F20.0) & 2 & & 1 & & 3 & \\
\hline Schizoaffective - depressive type (F25.I) & 0 & & 4 & & 4 & \\
\hline Other nonorganic psychoses (F28.0) & I & & 0 & & I & \\
\hline Any psychiatric disorder & 53 & (91.4) & 85 & $(92.4)$ & 138 & (92.0) \\
\hline
\end{tabular}

I. Comorbidity of drug and alcohol use disorders was present in three males.

2. Four males diagnosed with alcohol dependence (FIO.2) also had alcoholic hallucinosis (FI0.5)

3. One male had two neurotic disorders.

4. One female had two neurotic disorders.

Psychotic symptoms (schizophrenia, F20; schizoaffective disorder, F25; psychotic depression, F32.3; alcoholic hallucinosis, F10.5; and other non-organic psychoses, F28) were present in 14 patients $(9.3 \%)$.

\section{Conduct disorders}

Three patients were diagnosed with conduct disorder, which was $11.5 \%$ of those aged 18 years and under.

\section{Personality disorders}

At follow-up the PAS was administered to $74.0 \%$ of the original cohort $(n=111)$. Personality disorders were present in 51 cases $(45.9 \%)$ (see Table 3 ). Nineteen patients $(17.1 \%)$ met criteria for one personality disorder, $15(13.5 \%)$ for two and $17(15.3 \%)$ for three or more. The most common disorders were anxious, anankastic and paranoid. Personality trait accentuation was present in 37 patients $(33.3 \%)$ without a personality disorder. There was no gender difference in the presence or type of personality disorder.

\section{Comorbidity of psychiatric and personality disorders}

Of the 111 patients for which both psychiatric and personality assessments were completed, comorbidity of psychiatric and personality disorders was present in 49 cases $(44.1 \%)$. Of the 51 patients with a personality disorder, only two did not have a current psychiatric disorder. The frequency of comorbidity of psychiatric and personality disorders did not differ markedly between the two genders.

\section{DISCUSSION}

In a representative sample of DSH patients presenting to a general hospital in the UK, we found a high prevalence of both psychiatric $(92.0 \%)$ and personality $(45.9 \%)$ disorders, the most common psychiatric disorders being depression, substance use and anxiety disorders. The rates of psychiatric disorder found in this study are considerably higher than those reported in older UK studies which used systematic screening instruments (Newson-Smith \& Hirsch, 1979; Urwin \& Gibbons, 1979). The rates and profile of psychiatric disorders in this study are more similar to those reported by UK studies of completed suicides (Barraclough et al, 1974; Foster et $a l, 1997)$. One potential reason for the difference between the findings of this study and those from the 1970s might be a change in the characteristics of the DSH population over time. It is also possible that the use of a structured diagnostic schedule may have resulted in the over-diagnosis of mental disorders in suggestible patients. However, the extent of documented past psychiatric disorder suggests that such an effect, if present, would be small. In addition, discrepancies between the frequency of psychiatric diagnoses in DSH patients based on research interviews and those made in routine clinical consultations have also been reported by Suominen et al (1999). They found significantly higher rates of depression, alcohol dependence/ abuse and comorbidity of psychiatric disorders following research interviews in comparison to routine consultations. They concluded that this finding has important implications for clinical practice. Furthermore, recent studies from other countries have reported similar rates of psychiatric disorders in DSH patients to those found in this study (Ennis et al, 1989, 85\%; Suominen et al, 1996, 98\%; Gupta \& Trzepacz, 1997, 96\%; Ferreira de Castro et al, 1998, 86\%). Multiple psychiatric disorders were present in nearly half of our sample, which is similar to the findings of Suominen et al (1996).

\section{Psychiatric disorders}

We found depression to be by far the most common psychiatric diagnosis, with $70.7 \%$ of patients reaching ICD-10 criteria for a depressive episode. Surprisingly, nearly half the depressive episodes were severe or psychotic. Our findings replicate those of Suominen et al (1996), who diagnosed $66.7 \%$ 
Table 3 Personality disorders at time of follow-up interview

\begin{tabular}{|c|c|c|c|c|c|c|}
\hline \multirow[t]{2}{*}{ Personality disorder (ICD-10 classification) } & \multicolumn{2}{|c|}{ Males $(n=39)$} & \multicolumn{2}{|c|}{ Females $(n=72)$} & \multicolumn{2}{|c|}{ Total $(n=I I I)$} \\
\hline & $n$ & (\%) & $n$ & (\%) & $n$ & $(\%)$ \\
\hline Anxious: F60.6 & 7 & (I7.9) & 16 & $(22.2)$ & 23 & (20.7) \\
\hline Anankastic: F60.5 & 10 & $(25.6)$ & 12 & $(16.7)$ & 22 & $(19.8)$ \\
\hline Paranoid: F60.0 & 6 & $(15.4)$ & II & $(15.3)$ & 17 & (I5.3) \\
\hline Histrionic: F60.4 & 7 & (I7.9) & 7 & $(9.7)$ & 14 & $(12.6)$ \\
\hline Dependent: F60.7 & 4 & $(10.3)$ & 10 & (13.9) & 14 & $(12.6)$ \\
\hline Emotionally unstable: $\mathrm{F} 60.3$ & 5 & $(12.8)$ & 7 & (9.7) & 12 & $(10.8)$ \\
\hline Schizoid: F60.I & 3 & (7.7) & 3 & $(4.2)$ & 6 & (5.4) \\
\hline Dissocial: F60.2 & 3 & (7.7) & 3 & $(4.2)$ & 6 & (5.4) \\
\hline Any personality disorder & 20 & (5I.3) & 31 & $(43.1)$ & 51 & (45.9) \\
\hline
\end{tabular}

of patients with either major depression or depression not otherwise specified, and Beautrais et al (1996), who diagnosed $61.9 \%$ with major depression, but are somewhat higher than the rates in other studies (Ennis et al, 1989, 31.0\%; Gupta \& Trzepacz, 1997; 37.2\%). Our low prevalence figure for adjustment disorder $(2.7 \%)$ is in keeping with the findings of Suominen et al (1996) (3.0\%) and Ennis et al (1989) $(9.9 \%)$, but is lower than that found in other studies (Gupta \& Trzepacz, 1997, $35.8 \%$; Ferreira de Castro et al, 1998, $15.7 \%)$.

This study found alcohol dependence and harmful use to be the second most common psychiatric diagnosis $(26.7 \%)$, but it was not as common as in the Finnish study of Suominen et al (1996) $(53.5 \%)$ or in the Canadian study of Ennis et al (1989) (33.8\%). We found a lower prevalence of drug misuse and dependence $(8.7 \%)$ than Suominen et al (1996) $(12.3 \%)$ and Ennis et al (1989) (23.9\%). Anxiety disorders were fairly common $(14.0 \%)$ and of similar frequency to that reported by Suominen et al (1996) $(17.5 \%)$. The prevalence of eating disorders in this study $(10.7 \%)$ is much higher than that reported in other studies of DSH patients, for example Ennis et al (1989) and Suominen et al (1996) did not diagnose eating disorders in any of their patients. Schizophrenia and schizoaffective disorder were uncommon in this study, which is similar to the findings of other investigations.

Between-study comparisons with respect to the prevalence of psychiatric disorders are complicated by the use of different diagnostic classifications. We used ICD-10 criteria whereas most other studies have used versions of the DSM classification (Ennis et al, 1989; Beautrais et al, 1996; Suominen et al, 1996; Gupta \& Trzepacz, 1997; Ferreira de Castro et al, 1998). The main implication for using different diagnostic classifications is the lower threshold for an adjustment disorder diagnosis in DSM and a lower threshold for a mild depressive diagnosis in ICD-10. It is unlikely, however, that our finding of a high prevalence of depressive disorder and a low prevalence of adjustment disorder is due to misdiagnosis because the majority of depressive episodes were moderate or severe $(88.7 \%)$ and the duration of the depressive symptoms was longer than two months in $83.0 \%$ of cases.

Comparison with other studies is further hindered by most having included selected samples. For example, although Suominen et al (1996) in Finland had a systematic approach to identifying suitable patients, only $28 \%$ of the patients invited to participate were interviewed. Ennis et al (1989) in Canada studied only those patients who were admitted to an in-patient psychiatric crisis unit. Patients who were not admitted or who were admitted to other psychiatric units were not included, although they constituted nearly threequarters of the DSH patients. Both Beautrais et al (1996) in New Zealand and Gupta \& Trzepacz (1997) in the USA included only patients who had made a medically serious suicide attempt. Ferreira de Castro et al (1998) studied patients who were attending a suicide prevention facility, but it is unclear how patients were recruited or what proportion agreed to be interviewed.

In the present study there was a relatively high acceptance rate for interview
(69.1\%). There may have been some bias towards inclusion of patients with greater psychopathology, since a somewhat higher proportion of patients who agreed to participate were in current psychiatric care and had a history of previous DSH compared to those who did not participate (differences not statistically significant). However, the included patients were generally representative of the overall DSH population which presented to the hospital during the study period.

\section{Personality disorders}

The proportion of DSH patients in this study with a personality disorder $(45.9 \%)$ is similar to that found in previous studies (Ennis et al, 1989, 57.7\%; Suominen et al, 1996, 40.4\%; Ferreira de Castro et al, 1998, 50.6\%). Borderline personality disorder has been reported as the most common personality disorder in several studies of DSH patients (Ennis et al, 1989; Suominen et al, 1996; Gupta \& Trzepacz, 1997). One of its diagnostic features is recurrent threats or acts of self-harm. In this study, emotionally unstable personality disorder, of which borderline personality disorder is a sub-type, was less common than the anxious, anankastic and paranoid disorders. This may reflect insensitivity of the self-report version of the PAS in detecting borderline disorder. However, few studies have screened for the full range of personality disorders. For example, Nordentoft \& Rubin (1993) only reported on the presence of borderline and antisocial personality disorder. Thus, the previous perceptions of the nature of personality disorder in DSH patients may have been misrepresented. Our findings are similar to those of Dirks (1998), whose study was the only other one that used a standardised tool for the assessment of personality. $\mathrm{He}$ found paranoid and anxious, followed by impulsive, to be the most common personality disorders. The findings regarding personality disorder may have been somewhat different if we had been able to interview other informants (Zimmerman, 1994).

\section{Comorbidity}

The high prevalence of comorbidity of psychiatric and personality disorders $(44.1 \%)$ is similar to that reported by Suominen et al (1996) $(39.0 \%)$ in the only other study which examined comorbidity in a representative patient sample. The importance 
of comorbidity in suicidal behaviour is apparent from the study by Foster et al (1999) in which it increased the risk of suicide over six-fold compared with the risk in individuals with psychiatric disorders alone.

\section{Gender differences}

A striking finding of this study is that there were no significant gender differences in the prevalence and severity of depressive disorders, in the prevalence of anxiety disorders or in the frequency of comorbidity of psychiatric and/or personality disorders. However, there were significant gender differences in the rates of alcohol dependence or harmful use and eating disorders.

\section{Implications for the management of deliberate self-harm}

The high rates of psychiatric morbidity found in this study suggest that the assessment of DSH patients should include careful screening for psychiatric symptoms. This has implications for staff training. The high prevalence of depressive symptoms and the large number of patients with severe depressive episodes raises the question of whether affective disorders in DSH patients are under-recognised and under-treated. While psychosocial interventions are thought appropriate for a large proportion of patients (Heard, 2000), antidepressant treatment may also be indicated for a sizeable number. Alcohol-related disorders are also very common and require skilled detection and treatment. Deliberate self-harm patients can be non-compliant and difficult to engage in therapy (van Heeringen et al, 1995). The comorbidity of psychiatric and/or personality disorders complicates the management of patients such that effective treatment may require collaboration between multiple agencies.

\section{ACKNOWLEDGEMENTS}

This study and the Oxford Monitoring System for Attempted Suicide were funded by Anglia and Oxford NHS Executive Regional Research Committee. Keith Hawton is also supported by Oxfordshire Mental Healthcare Trust. Camilla Haw is supported by St Andrew's Hospital, Northampton. We would like to thank the staff in the Department of Psychological Medicine (Dr Christopher Bass, Karen Carroll, Barbara Chishom, Sharon Codd, Dr Eleanor Feldman, Dave Roberts, Jill Roberts, Heather Weitzel and Linda Whitehead) for their considerable assistance with the study and also Louise Harriss for

\section{CLINICAL IMPLICATIONS}

Psychiatric disorder is very common in deliberate self-harm (DSH) patients and therefore they need careful screening for psychiatric symptoms.

- Many DSH patients have depression of moderate or severe severity, therefore treatment with antidepressants may often be indicated for these patients.

Many DSH patients have comorbid disorders and may need an integrated care package involving multiple agencies.

\section{LIMITATIONS}

- Not all potential subjects could be included in the study and there may have been a small bias towards patients with somewhat greater psychopathology being included in the study sample.

- Psychiatric disorder was assessed using a structured clinical diagnostic schedule which may have influenced the reporting of symptoms.

- Personality disorders and traits were only assessed in patients who were interviewed at follow-up.

CAMILLA HAW, MRCPsych, St Andrew's Hospital, Northampton; KEITH HAWTON, DM, KELLY HOUSTON, BA, ELLEN TOWNSEND, PhD, Centre for Suicide Research, University of Oxford, Department of Psychiatry, Warneford Hospital, Oxford

Correspondence: Professor Keith Hawton, Centre for Suicide Research, University of Oxford, Department of Psychiatry, Warneford Hospital, Oxford OX3 7JX, UK. E-mail:

keith.hawton@psychiatry.ox.ac.uk

(First received 17 November 1999, final revision 29 June 2000, accepted 10 July 2000)

her help with the analysis of data from the Monitoring System. Oxford is the UK Centre in the WHO/ Euro Multicentre Study on Parasuicide.

\section{REFERENCES}

Barraclough, B., Bunch, J., Nelson, B., et al (1974) A hundred cases of suicide: clinical aspects. British Journal of Psychiatry, 125, 355-373.

Beautrais, A., Joyce, P., Mulder, R., et al (1996) Prevalence and comorbidity of mental disorders in persons making serious suicide attempts: a casecontrol study. American Journal of Psychiatry, 153, 1009-1014.

Dean, A., Dean, J., Coulombier, D., et al (1994) Epilnfo Version 6: A Word Processing Database and Statistics Program for Epidemiology on Microcomputers. Atlanta, GA: Centers for Disease Control and Prevention.

Dirks, B. (1998) Repetition of parasuicide: ICD-I0 personality disorders and adversity. Acta Psychiatrica Scandinavica, 98, 208-213.

Ennis, J., Barnes, R. A., Kennedy, S., et al (1989) Depression in self-harm patients. British journal of Psychiatry, 154, 4I-47.
Ferreira de Castro, E., Cunha, M., Pimenta, F., et al (1998) Parasuicide and mental disorders. Acto Psychiatrica Scandinavica, 97, 25-31.

Foster, T., Gillespie, K. \& McClelland, R. (1997) Mental disorders and suicide in Northern Ireland. British Journal of Psychiatry, I70, 447-452.

_ _ , _ , et al (1999) Risk factors for suicide independent of DSM-III-R Axis I disorder. Casecontrol psychological autopsy study in Northern Ireland. British Journal of Psychiatry, 175, 175-179.

Gupta, B. \& Trzepacz, P. (1997) Serious overdosers admitted to a general hospital: comparison with nonoverdose self-injuries and medically ill patients with suicidal ideation. General Hospital Psychiatry, 19 209-215.

Hawton, K. \& Fagg, J. (1988) Suicide, and other causes of death, following attempted suicide. British Journal of Psychiatry, 152, 359-366.

_ , _ , Simkin, S., et al (1997) Trends in deliberate self-harm in Oxford, 1985-1995. Implications for clinical services and the prevention of suicide. British Journal of Psychiatry, I7I, 556-560.

_ , Simkin, S., Malmberg, A., et al (1998) Suicide and Stress in Farmers. London: The Stationery Office.

Heard, H. (2000) Psychotherapeutic approaches to suicidal ideation and behaviour. In The International 
Handbook of Suicide and Attempted Suicide (eds K. Hawton \& K. van Heeringen), pp. 503-518. Chichester: John Wiley \& Sons.

Kapur, N., House, A., Creed, F., et al (1998) Management of deliberate self-poisoning in adults in four teaching hospitals: descriptive study. British Medical Journal, 316, 831-832.

Kerkhof, A., Bernasco, W., Bille-Brahe, U., et al (1989) WHO/EU Multicentre Study on Parasuicide: European Parasuicide Study Interview Schedule (EPSIS). Leiden: Leiden University, Department of Clinical, Health and Personality Psychology.

Newson-Smith, J. \& Hirsch, S. (1979) Psychiatric symptoms in self-poisoning patients. Psychological Medicine, 9, 493-500.

Nordentoft, M. \& Rubin, P. (1993) Mental illness and social integration among suicide attempters in

Copenhagen. Acta Psychiatrica Scandinavica, 8, 278-285.
Platt, S., Bille-Brahe, U., Kerkhof, A., et al (1992) Parasuicide in Europe: the WHO/EURO multicentre study on parasuicide. I. Introduction and preliminary analysis for 1989. Acta Psychiatrica Scandinavica, 85, 97-104.

Suominen, K., Henriksson, M., Suokas, J., et al (1996) Mental disorders and comorbidity in attempted suicide. Acta Psychiatrica Scandinavica, 94, 234-240.

\section{_ , Isometsa, E., Henriksson, M., et al (1999)}

Consultation versus research diagnoses of menta disorders among suicide attempters. Nordic Journal of Psychiatry, 53, 253-256.

SPSS (1999) SPSS Base 9.0 Users Guide. Upper Saddle River, NJ: Prentice Hall.

Tyrer, P., Alexander, J. \& Ferguson, B. (1988) Personality Assessment Schedule (PAS). In Personality

Disorder: Diagnosis, Management and Course (ed.
P. Tyrer), pp. 140-167. London: Butterworth/ Wright.

Urwin, P. \& Gibbons, J. (1979) Psychiatric diagnosis in self-poisoning patients. Psychological Medicine, $\mathbf{9}$ 50I-507.

van Heeringen, K., Jannes, S., Buylaert, W., et al (1995) The management of non-compliance with referral to out-patient after-care among attempted suicide patients: a controlled intervention study. Psychological Medicine, 25, 963-970.

World Health Organization (1993) The ICD-10 Classification of Mental and Behavioural Disorders; Diagnostic Criteria for Research. Geneva: WHO.

Zimmerman, M. (1994) Diagnosing personality disorders: a review of issues and research methods. Archives of General Psychiatry, 5I, 225-245. 